$\xi_{p}=$

\title{
Synthesis and Evaluation of Novel Naphthenate Inhibitor Demulsifier from Fatty Hydrazide Derivatives
}

\author{
N. Borhan ${ }^{1,2 *}$, A. Ramli ${ }^{2}$, I.K. Salleh ${ }^{1}$ \\ ${ }^{I}$ PETRONAS Research Sdn Bhd, Lot 3288 \& 3289, Off Jalan Ayer Itam, Kawasan Institusi Bangi, 43000, Kajang, Selangor \\ ${ }^{2}$ Fundamental and Applied Sciences Department, Universiti Teknologi PETRONAS, 32610 Seri Iskandar, Perak, Malaysia \\ *Corresponding author E-mail: noorazlenawati_borhan@petronas.com.my
}

\begin{abstract}
The production of crude oil contained Alkaline-Surfactant-Polymer (ASP)-chemical enhance oil recovery (CEOR) has a significant detrimental effect on flow assurance mainly for formation of microemulsion which is thermally stable and difficult to break and separated into clean crude oil and water phase. Quality of clean crude oil for saleability is important through achievement of crude oil dehydration in terms of basic sediment and water (BS\&W) specification less than $0.5 \%$. This paper outlines a case-study where stable microemulsions were formed following mixing of crude oil and ASP brine, requiring operationally intensive remediation. Finally, novel palm oil-derived fatty hydrazide Naphthenate Inhibitor (NI)-Demulsifier were synthesized, formulated and tested using dynamic laboratory tests using a multifunctional mini flow loop (MMFL). Under dynamic laboratory test, crude oil, prepared produced water and ASP were mixed under high shear at separator temperature and pressure. The NI-demulsifiers chemical injection was carried out after microemulsions were formed before the separator, representing a wellhead injection point and for a sufficient time to allow the microemulsion system to reach equilibrium. This work demonstrates the importance of considering the impact of ASP-EOR fluids on existing emulsion and using an appropriate laboratory technique to evaluate potential mitigating treatments for oil-water separation technology. The effects of temperature and water cut on microemulsion stability are shown and the NI-demulsifier demonstrated excellence in demulsifying and dehydration at minimal dosage.
\end{abstract}

Keywords: Demulsifier, EOR (Enhance Oil Recovery), Fatty Hydrazide, Naphthenate Inhibitor

\section{Introduction}

The phase behavior of produced crude oil fluid contained ASP coming from reservoir to central processing platform contained water in oil (W/O) microemulsion and oil in water $(\mathrm{O} / \mathrm{W})$ microemulsion. W/O microemulsion or inverse microemulsion were fluid phase of water as dispersed phase while oil as continuous phase. W/O micelles were generated by rigid interfacial films which form a skin on water droplets and prevent the water droplets from coalescence by creating a stable colloidal structure. O/W microemulsion were fluid phase of oil as the dispersed phase while water as continuous phase and in a reverse micelles formation [1-2]. Shearing of fluids on passage to separator create a small droplet size which become electrostatically stable as similar charged droplets will repel with each other and not coalescence to form bigger diameter drops for easy separation [3-5].

Alkaline of sodium carbonate $\left(\mathrm{Na}_{2} \mathrm{CO}_{3}\right)$ from ASP caused high $\mathrm{pH}$. At the production system, ASP produced water conditions at $\mathrm{pH}$ between 9-10. The increased in the $\mathrm{pH}$ will cause the high molecular weight $(\mathrm{Mw})$ naphthenic acids (NAs) to dissociate even if the pKa value of light (i.e. low $\mathrm{Mw}$ ) and heavy (i.e. high $\mathrm{Mw}$ ) NAs are close. Low Mw aliphatic NAs are actually slightly soluble in water. In an acidic medium, they are protonated and become insoluble in water, whereas in basic medium, they dissolved in water as salts [6]. The dissociation of the NAs (i.e. de-protonated under anionic state) with NAs with $150-230 \mathrm{Mw}$ dissociated at $\mathrm{pH}$ 6.2 while most of NAs with Mw between 230-530 will dissociate at $\mathrm{pH}$ 7.2. In order for the NAs with heaviest Mw to dissociate, the $\mathrm{pH}$ must be increased to 11 [7]. NAs dissociation at $\mathrm{pH} 3-5$ contained almost $50 \%$ predominantly tricyclic and bicyclic structures while dominant NAs of bicyclic and tricyclic structures were observed at $\mathrm{pH} 8$. On the other hand, almost $22 \%$ NAs were separated at $\mathrm{pH}$ between 9 and 10 with their dominant NAs constituents with 3, 4 and 5 membered rings. The NAs with 3 rings were found to be more hydrophilic than NAs with 1 or 2 rings [8].

Dissociation of the NAs and its phase behavior is their ability to self-organize through formation of aggregates as the RCOO- moieties become reactive towards metal cations and form complex with calcium ion $\left(\mathrm{Ca}^{2+}\right)$ and sodium ion $\left(\mathrm{Na}^{+}\right)$forming $(\mathrm{RCOO})_{2} \mathrm{Ca}$ and $\mathrm{RCOONa}$ as dimers, micelles and higher order structures. These aggregation properties resulted from the amphiphilic nature (presence of both hydrophobic and hydrophilic parts) of the NAs itself. The formation of micelles and other variance aggregates (e.g. reverse micelles) has been suggested to be restricted to a few molecular species, and depends on the bulk phase (i.e. oil or water), $\mathrm{pH}$ and NAs concentrations. Increases in the total concentration of ionized NAs (RCOO-) at the interface decreases the interfacial tension (IFTs) due to electrical double layer effect and increase in dilatational elasticities [9].

Chemical methods by blending of naphthenate inhibitors (NIs) and demulsifiers is the mitigating approach for emulsion resolution as well as to accelerate the crude oil dehydration process. NIs inhibits the surface active properties which congregate at oil-water interface and form a layer that prevents the interactions between protonated NAs and cations (i.e. $\mathrm{Na}^{+}$and $\mathrm{Ca}^{2+}$ ) in the water phase. Demulsification is an emulsion reversal process by destructing and 
reducing the thickness of oil-water interfacial film, allowing the W/O droplets to coalesce. In the structure of many demulsifiers, the hydrophilic parts are composed of oxyethylene, hydroxyl, carboxyl or amine groups, while the hydrophobic parts contain alkyl, alkylphenol or oxypropylene groups. The hydrophobic and hydrophilic characters of a demulsifier will determine its effectiveness in W/O emulsion destabilisation, as well as $\mathrm{O} / \mathrm{W}$ minimization [10-12]. In this paper, we report the novel chemical compound of palm oil derivatives as hybrid NI-demulsifier for mitigation approach for W/O and O/W microemulsion from ASP-EOR.

\section{Material and Method}

The materials and methods used for the experiment are describe below.

\subsection{Extraction of Naphthenic Acids from Crude Oil and Mass Spectrometry}

Naphthenic Acid was extracted using Ion Exchange Resin (AcidIER) methods. QAE Sephadex A-25 which is a sugar base resin (poly-1,6-glucose) with diethyl-(-2-hydroxypropyl) aminoethyl ion exchange group was used as the ion exchange resin. The extracted naphthenic acid samples were analysed using FTIR-MS (Thermo Fisher Scientific) and 2D Linear Quadrupole Ion Trap Fourier Transform (LTQ-FT) mass spectrometry (positive ionization mode ESI-MS) Ultra 7 Tesla system.

\subsection{Synthesis of Demulsifier Compound}

0.02 mole of maleic acid anhydride (1) was reacted with 1.175 mole of methanol under esterification process at 80 to $90{ }^{\circ} \mathrm{C}$. The produced intermediate compound of monomethyl ester (2), CAS\#3052-50-4. Compound (2) was then reacted with 0.005 mole of palm fatty hydrazide (3) to produce final compound (4) in a $250 \mathrm{~mL} 3$-neck flask fitted with dean stark apparatus for 6 hours. $100 \mathrm{~mL}$ mixture of methyl isobutyl ketone (MIBK) and N, Ndimethylformamide (DMF) at 1:1 ratio was used as catalyst. The compound (4) was washed with distilled water until no solvent odour and filtered. Compound (4) was dried under humidity drying at room condition. The yield of compound (4) calculated from percentage of $\mathrm{C}, \mathrm{H}, \mathrm{N}, \mathrm{O}$ elemental analysis shows almost $95 \%$ of purity. Figure 1 shows the synthetic scheme and conditions used for the reaction.

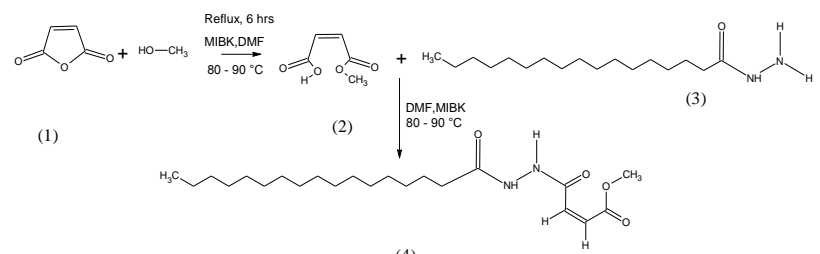

Fig. 1: Synthetic scheme for $\stackrel{(4)}{5}$ nthesis of demulsifier compound

\subsection{Characterization of the Synthesized Compound}

Elucidation of the synthesized compound was recorded using ${ }^{1} \mathrm{H}$ NMR and ${ }^{13} \mathrm{C}$ NMR on a Bruker $400 \mathrm{MHz}$ SB Ultra Shield ${ }^{\mathrm{TM}}$. The NMR spectra were recorded in $\mathrm{CDCl}_{3}$ and chemical shifts recorded were internally referenced to TMS $(0 \mathrm{ppm})$. Fourier transform infrared (FT-IR) spectra were obtained using a Perkin Elmer Spectrum $^{\text {TM }} 400$ FT-IR spectrophotometer.

\subsection{Dynamic Condition Testing by MMFL}

The dynamic low loop test is shown in Figure 2. Tests were carried out at $30^{\circ}$ to $60^{\circ}$ at 4.5 bar with a $40-60 \%$ water cut off match field separator conditions. Crude oil and brine were injected into a mixing cell equipped with a sealed homogeniser operating at 13,500 rpm. The combined fluids then flowed from the mixing cell through the two in-line filters. The first was a coarse filter/baffle and the second was a $7 \mu \mathrm{m}$ sintered metal filter. The differential pressure (dP) across the fine filter was measured and plotted, allowing assessment of the viscosity of the fluids and any blockages arising from solids formation. The fluids then entered a glass separator where the oil/brine interface and any emulsion formed were observed and photographed. The entire apparatus is housed inside an oven and pressurized to replicate the conditions of a low-pressure separator in the field.

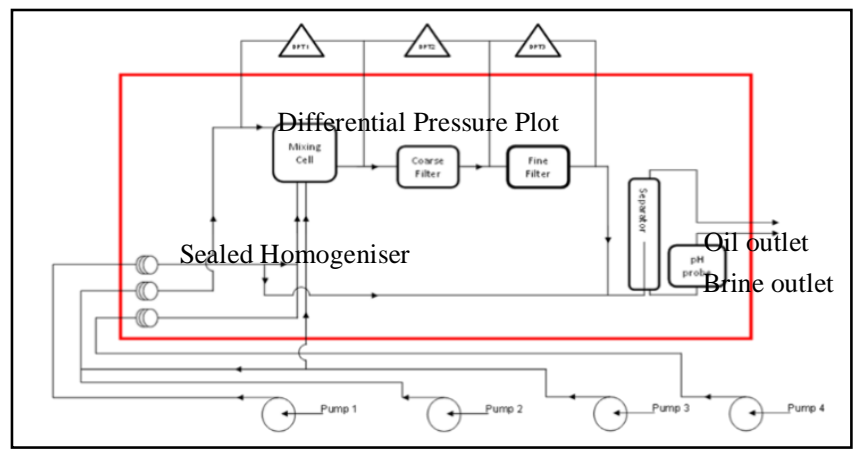

Fig. 2: Schematic of the MMFL

Table 1 shows the properties of the crude oils NAs while Table 2 shows the brine compositions used in this work. Table 3 shows the composition of the ASP injection water used.

Table 1: Details of Crude Oils

\begin{tabular}{|lll|}
\hline Field & $\begin{array}{l}\text { Total Acid Number } \\
(\mathbf{m g ~ K O H} / \mathbf{g})\end{array}$ & Monoprotic acids \\
\hline A & 0.50 & $\begin{array}{l}\text { Saturated acyclic (DBE=1) and higher } \\
\text { DBE of } 4 \text { to 6 NAs species }\end{array}$ \\
\hline B & 0.08 & Saturated acyclic (DBE=1) \\
\hline
\end{tabular}

Table 2: Details of Brine Compositions ${ }^{\mathrm{a}}$

\begin{tabular}{cccccccccccc} 
Ion & $\mathbf{N a}$ & $\mathbf{C}$ & $\mathbf{M}$ & $\mathbf{K}$ & $\mathbf{B}$ & $\mathbf{S r}$ & $\mathbf{F}$ & $\mathbf{S O}$ & $\mathbf{H C}$ & $\mathbf{C l}$ \\
$\mathbf{( m g} /$ & & $\mathbf{a}$ & $\mathbf{g}$ & & $\mathbf{a}$ & & $\mathbf{e}$ & $\mathbf{4}$ & $\mathbf{\mathbf { O } _ { 3 }}$ & \\
$\mathbf{\text { L) }}$ & & & & & & & & & & \\
\hline $\begin{array}{c}\text { Field } \\
\text { A }\end{array}$ & 3,42 & 10 & 26 & 38 & 0 & 1. & 2. & 36 & 4,33 & 3,05 \\
$(\mathbf{P W})$ & & & & & & 4 & 4 & & 9 & 3 \\
\hline $\begin{array}{c}\text { Field } \\
\text { B }\end{array}$ & 4,55 & 14 & 16. & 51. & 0. & 1. & 0. & 1.7 & 4,74 & 4,44 \\
$(\mathbf{P W})$ & & & 5 & 7 & 9 & 3 & 3 & & 7 & 3 \\
\hline
\end{tabular}

${ }^{\mathrm{a}} \mathrm{Ba}, \mathrm{Fe}$ and $\mathrm{SO}_{4}$ were omitted

Table 3: Details of ASP Injection Water

\begin{tabular}{lcc}
\hline \multicolumn{1}{c}{ Component } & $\begin{array}{c}\text { Concentration } \\
\text { Field A }\end{array}$ & $\begin{array}{c}\text { Concentration } \\
\text { Field B }\end{array}$ \\
\hline $\begin{array}{l}\text { Sodium carbonate } \\
\text { (alkali) }\end{array}$ & $1 \mathrm{wt} \%$ & $1 \mathrm{wt} \%$ \\
\hline Surfactant B & $0.5 \mathrm{wt} \%$ & $0.3 \mathrm{wt} \%$ \\
\hline Polymer A & $2,000 \mathrm{ppm}$ & $1,000 \mathrm{ppm}$ \\
\hline Diluent & $\begin{array}{c}16,000 \mathrm{ppm} \mathrm{NaCl} \\
\text { brine }\end{array}$ & $\begin{array}{c}20,000 \mathrm{ppm} \mathrm{NaCl} \\
\text { brine }\end{array}$ \\
\hline
\end{tabular}

\subsection{Water-in-Oil Determination by Karl Fischer Titra-} tion

The water-in-oil content in samples collected from the oil outlet of the separator in the flow loop during tests was determined by Karl Fischer titration using a Metrohm 795 KFT Titrino instrument. The samples were homogenised at 13,500 rpm for 60 seconds using an IKA Ultra Turrax T25 homogeniser equipped with an S25KV-18G dispersing element to reincorporate any water that had settled on storage. All samples were analysed in duplicate using the automatic titration instrument. Oil samples were taken after 30, 60 and 90 minutes during tests and the values given are in the range of the water contents obtained from these samples. This 
method therefore gives the water content of the oil effluent flowing from the separator. The samples were then allowed to stand at the test temperature for 4 hours without further agitation to determine the effect of increasing the residence time in a field separator or static tank. A further aliquot for analysis was then taken from the uppermost layer without further homogenization.

\section{Result and Discussion}

\subsection{Naphthenic Acids Mass Spectrometry}

Figure 3 (a) shows that crude oil A contains a broad range of lower molecular weight (Mw) acids (250-600), with a small fraction of moderate molecular weight $(650-900)$ NAs present. Table 4 shows the NAs distribution in crude oil A with $19.5 \%$ monocarboxylic acids. Double bond equivalent (DBE) analysis of monocarboxylic acids of crude $\mathrm{A}$ reveals that it contains a mixture of saturated, acyclic $\left(\mathrm{DBE}=1, \mathrm{C}_{20-30}\right)$ and higher $\mathrm{DBE}$ of 2-3 at $\mathrm{C}_{20-}$ ${ }_{30}$ and 4-6 around $\mathrm{C}_{30}$ acids (Fig. 3 (b)). Figure 4 shows that crude oil $\mathrm{B}$ contains a high percentage of lower Mw acids, with a bulk fraction of molecular weight $(250-500)$ and small fraction of $\mathrm{Mw}$ 620 NAs. Table 5 shows the NAs distribution in crude oil A with 4.5\% monocarboxylic acids. DBE analysis of monocarboxylic acids of crude $\mathrm{B}$ reveals that it contains a mixture of saturated, acyclic $\left(\mathrm{DBE}=1, \mathrm{C}_{18-22}\right)$ and $\mathrm{C}_{30}$ with 4-6 acids.
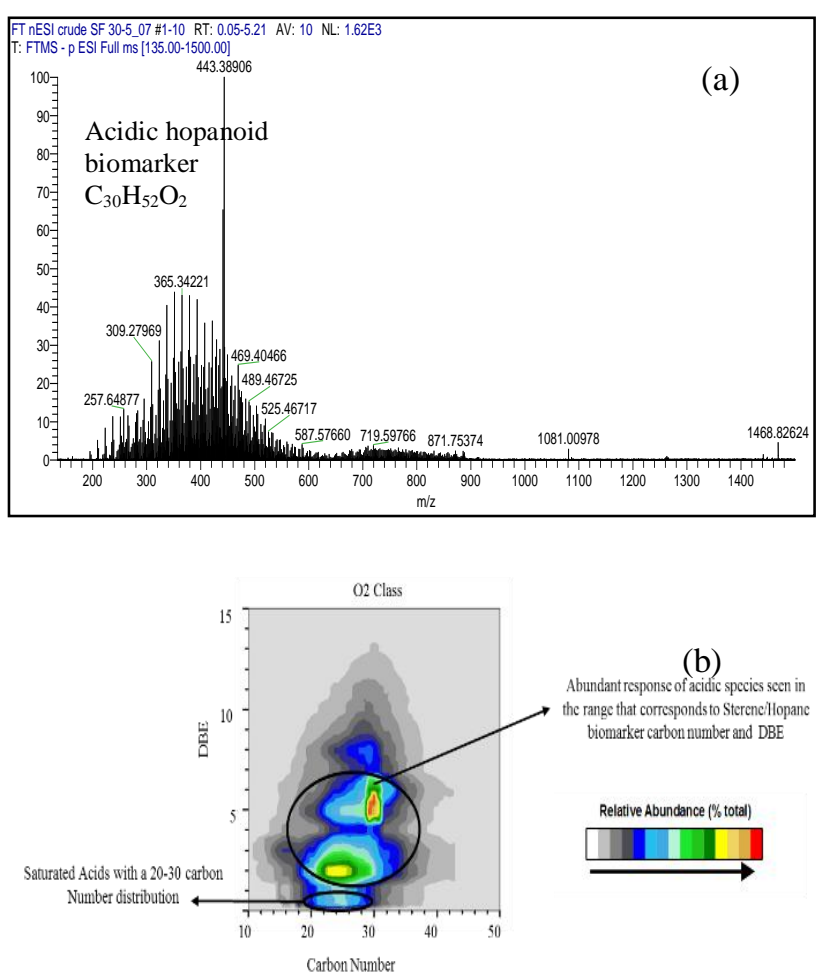

Fig. 3: (a) Crude Oil A Mass Spectroscopy Chromatogram and (b) DBE of $\mathrm{O}_{2}$ acids, $\mathrm{RCO}_{2} \mathrm{H}$ class

Table 4: NAs Distribution from Crude Oil A

\begin{tabular}{c|c|cc}
\multicolumn{5}{c}{ Table 4: NAs Distribution from Crude Oil A } \\
\hline No of ring & Z & \multicolumn{2}{c}{ \% Rel Ab. O2 Class } \\
\hline 0 & 0 & Saturates & 9.9 \\
1 & 2 & Monocyclic & 19.5 \\
2 & 4 & Dicyclic & 15.1 \\
3 & 6 & Tricyclic & 7.5 \\
4 & 8 & Tetracyclic & 14.4 \\
5 & 10 & 5 DBE & 11.8 \\
6 & 12 & 6 DBE & 6.0 \\
7 & 14 & 7 DBE & 6.3 \\
8 & 16 & 8 DBE & 3.9 \\
9 & 18 & 9 DBE & 2.6 \\
10 & 20 & 10 DBE & 2.1 \\
11 & 22 & 11 DBE & 1.1 \\
\hline
\end{tabular}
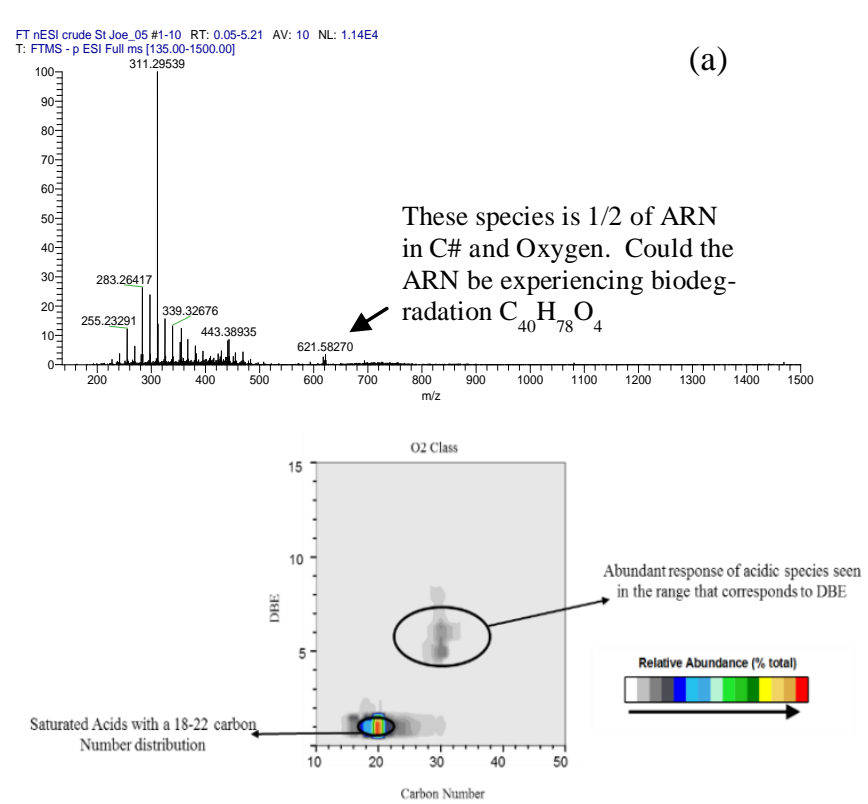

Fig. 4: (a) Crude Oil B Mass Spectroscopy Chromatogram and (b) DBE of $\mathrm{O} 2$ acids, $\mathrm{RCO}_{2} \mathrm{H}$ class (b)

Table 5: NAs Distribution from Crude Oil B

\begin{tabular}{c|c|cc}
\multicolumn{5}{c}{ Table 5: NAs Distribution from Crude Oil B } \\
\hline No of ring & Z & \multicolumn{2}{c}{ \% Rel Ab. O2 Class } \\
\hline 0 & 0 & Saturates & 66.8 \\
1 & 2 & Monocyclic & 4.5 \\
2 & 4 & Dicyclic & 2.9 \\
3 & 6 & Tricyclic & 1.1 \\
4 & 8 & Tetracyclic & 7.2 \\
5 & 10 & 5 DBE & 7.6 \\
6 & 12 & 6 DBE & 3.4 \\
7 & 14 & 7 DBE & 3.4 \\
8 & 16 & 8 DBE & 1.6 \\
9 & 18 & 9 DBE & 1.45 \\
\hline
\end{tabular}

\subsection{Characterization of Synthesis Compound}

The FTIR spectra of synthesis compound in the waxy solid state (Figure 5) shows absorption bands at 2850 and $2917 \mathrm{~cm}^{-1}$ corresponding to stretching of long alkyl chain of asymmetric and symmetric stretch vibration of $\mathrm{CH}_{3}, \mathrm{CH}_{2}$ and $\mathrm{CH}$. The asymmetric vibrations $v_{\text {as }}(\mathrm{N}-\mathrm{H})$ group stretching bands for secondary amide appears at $3475 \mathrm{~cm}^{-1}$ and symmetric vibrations $v_{\mathrm{s}}(\mathrm{N}-\mathrm{H})$ at 3233 $\mathrm{cm}^{-1}$. A broad intense band of symmetric stretching vibrations of $\mathrm{C}=\mathrm{O}$ amide $\mathrm{II}$ resonated at $1598 \mathrm{~cm}^{-1}$ and a weak vibration of $\mathrm{C}=\mathrm{O}$ ester at $1703 \mathrm{~cm}^{-1}$. Absorption band of C-N stretching is observed between 1024-1059 $\mathrm{cm}^{-1}$. The $-\mathrm{CH}_{3}$ absorption band is observed at $1380 \mathrm{~cm}^{-1}$. C $=\mathrm{C}$ absorption band is observed at $1467 \mathrm{~cm}^{-1}$ and weak $\mathrm{C}-\mathrm{O}$ band of ester is observed at $1171 \mathrm{~cm}^{-1}$.

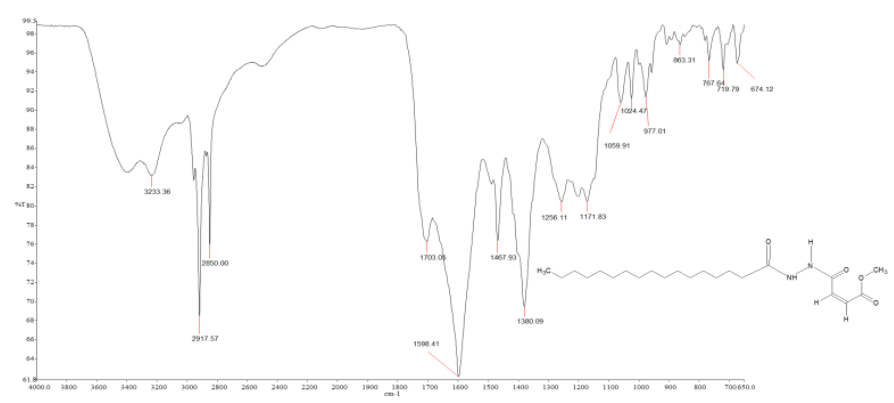

Fig. 5: FTIR spectrum of synthesis compound

The proton and carbon chemical shift assignment (Figure 6a and 6b). Figure 6a showed signal at: $\mathrm{CDCl}_{3} \delta \mathrm{ppm}=0.88$ ( \#C19, 31, m, 6H ), 1.20 ( \#C26, 27, m, 3H ), 1.23 ( \#C18, 20, 21, 22, 23, 24, $25,28,29,30,27, \mathrm{~s}, 19 \mathrm{H}$ ), 1.59 (\#C17, m, 2H ), 2.28 (\#C16, m, 
3H ), 2.90 ( \#C13, m, 3H ), 5.81 ( \#C8a,9a, br s,3H ), 7.32 (\#N3a, m, 1H ), 7.99 (\#N2, s(AA'BB'), 4H).

Figure $6 \mathrm{~b}$ showed signals at : $\mathrm{CDCl}_{3} \delta \mathrm{ppm}=13.59(\# \mathrm{C} 31)$, 21.93(\#C30), 24.11 (\#C17), 28.83 (\#C20), 28.88 (\#C19), 28.99 (\#C18), 29.13 (\#C21), 29.17 (\#C26), 29.81 (\#C22,23,24,25), 30.89 (\#C27), 31.40 (\#C28), 35.16 (\#C29), 35.98 (\#C16), 52.24 (\#C13), 131.18 (\#C9), 134.36 (\#C8), 164.56 (\#C5), 165.16 (\#C10),166.69 (\#C1).
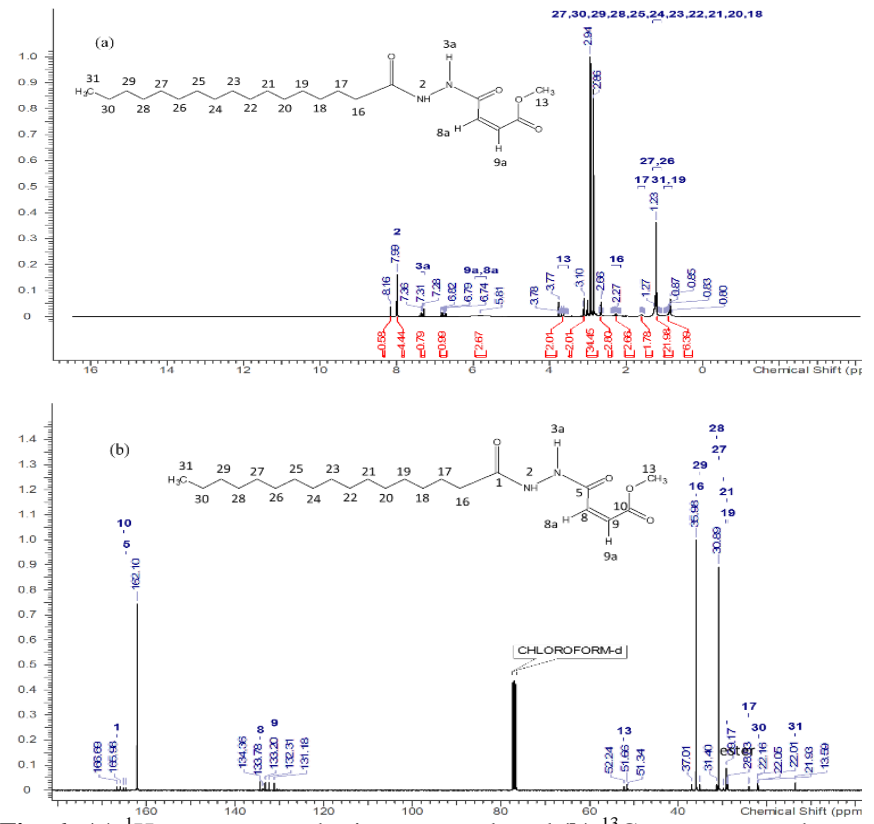

Fig. 6: (a) ${ }^{1} \mathrm{H}$ spectrum synthesis compound and (b) ${ }^{13} \mathrm{C}$ spectrum synthesis compound

\subsection{ASP-EOR microemulsion behavior and NI- Demulsifier Performance by MMFL}

Under non-ASP EOR scenario, when produced water (PW) was mixed with crude oil B at $30{ }^{\circ} \mathrm{C}$, a rag layer is formed [13]. The upper oil phase has low water content $(0.5-1.0 \%)$ and the lower brine phase appeared cloudy as shown in Figure 7. No further separation of water from the oil phase occurred upon standing at $30{ }^{\circ} \mathrm{C}$ for 4 hours. When ASP water was used instead, a severe microemulsion was formed that filled the separator with no separate oil phase present. The water in oil content of the microemulsion is between $18-23 \%$. A small amount of oil ( $1-2 \%$ water $)$ was separated from the microemulsion upon standing at $30{ }^{\circ} \mathrm{C}$ for 4 hours, leaving a microemulsion with $23-25 \%$ oil in water content. The volume of the separated oil was less than $10 \%$ of the total microemulsion volume. This indicates that increasing the separation time does not have a significant effect on the amount of oil separated.

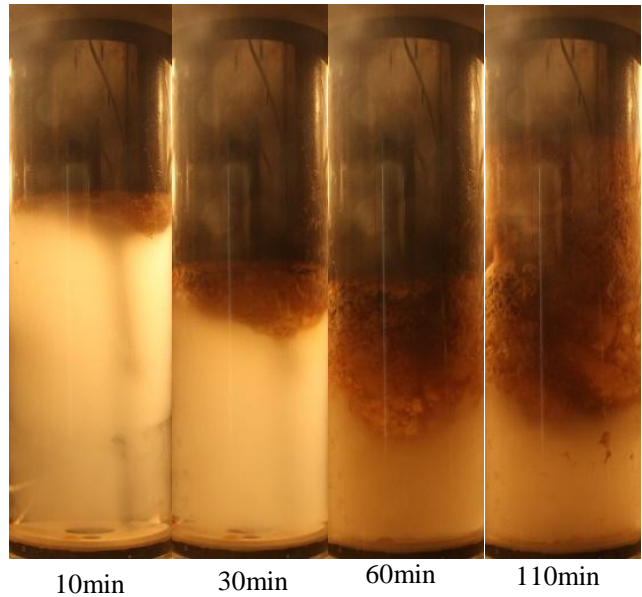

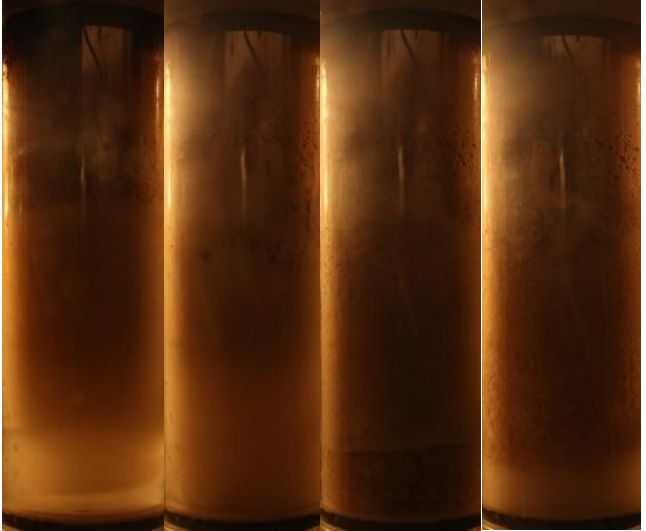

10min 30min 60min 130min

Fig. 7: Crude oil B emulsion behavior pictures of before (above) and after (bottom) with produced ASP ratio PW: ASPW (80:20), Pressure $=4.5 \mathrm{bar}$, Temperature $=30^{\circ} \mathrm{C}$, water cut $=55 \%$

The differential pressure of crude oil A shows the influence of high viscosity microemulsion fluids in the high $\mathrm{pH}$ condition nearing to 9 as per Figure 8. As expected, higher Mw NAs in crude oil A with 3, 4 and 5 membered rings will be protonated and becomes soluble in water and has affinity to form micelles of W/O and $\mathrm{O} / \mathrm{W}$ emulsions. Increasing the $\mathrm{pH}$ causes higher charges layers and more water soluble stoichiometry, whereas more branched and rigid acid structures cause steric hindrance, which may counteract in formation of sodium naphthenates soaps. This scenario is observed when produced water (PW) was mixed with the crude oil at $30{ }^{\circ} \mathrm{C}$ where a dark emulsion layer of wet oil formed indicating W/O emulsions [13]. The upper oil phase has high water content (14-33\%) and the lower brine phase appeared milky. When ASP water was used, a severe microemulsion was formed that filled the separator with no separate oil phase present. The water in oil content of the microemulsion analysed as 35-37\%. Effluent microemulsion samples separated upon standing at $30{ }^{\circ} \mathrm{C}$ for 4 hours to give separate oil (2-4\%) and cloudy brine phase with a sharp interface. This indicates that, under these conditions, additional residence time is required for adequate separation using a static tank in the field.

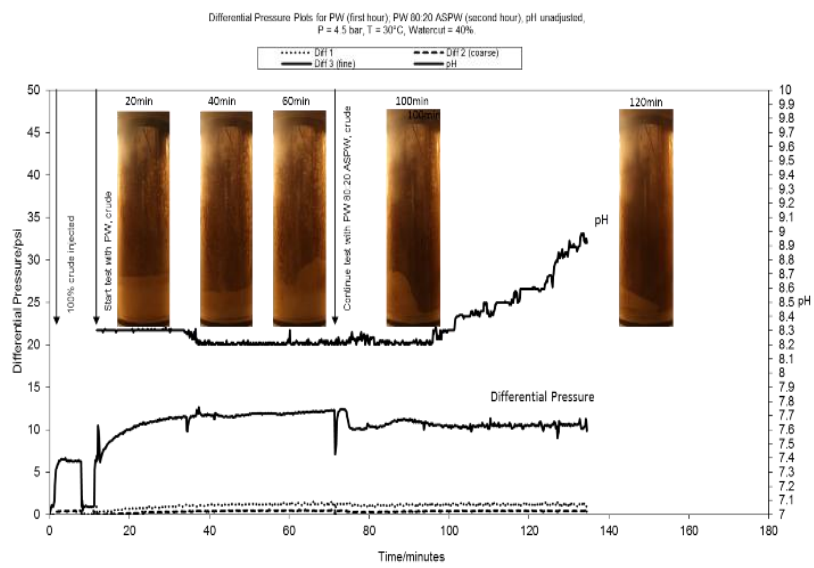

Fig. 8: Crude oil A emulsion behavior pictures and its differential pressure before and after with produced ASP ratio PW: ASPW (80:20), Pressure = 4.5bar, Temperature $=30^{\circ} \mathrm{C}$, water cut $=40 \%$

Table 6 shows the effect of altering water cut for crude oil A for PW and ASP tests at several temperatures. A broad trend was observed where microemulsions are more severe at higher water cut with higher water percentages recorded for the oil effluent. This supports the theory of protonated high Mw NAs become more partitioning and soluble in water phase and increasing or water cut increases the concentration of ionized NAs at the oilwater interface $[8,14]$. 
Table 6: Karl Fischer water-in-oil percentages in crude oil A

\begin{tabular}{l|c|c|cc}
\hline & $\begin{array}{c}\text { Temperature, } \\
{ }^{\circ} \mathrm{C}\end{array}$ & $\begin{array}{c}\text { Water } \\
\text { cut, } \\
\%\end{array}$ & Water -in -oil , \% \\
\hline & & & Time $=0 \mathrm{hr}$ & $\begin{array}{c}\text { Time }=4 \\
\mathrm{hr}\end{array}$ \\
PW/Blank & 30 & 40 & $15-24$ & $15-17$ \\
ASP/Blank & 30 & 40 & $35-37$ & $2-4$ \\
PW/Blank & 60 & 40 & 13 & 12 \\
ASP/Blank & 60 & 60 & 60 & 50 \\
ASP/Blank & 80 & 60 & 60 & 5 \\
\hline
\end{tabular}

NI-Demulsifier formulations as shown in Table 7 were injected between the filter and the separator as a solution in toluene and the concentrations given are with respect to total fluids. This is more representative of the field situation, where a microemulsion is likely to be formed downhole with chemical treatment only added topsides.

Table 6: Composition of formulations

\begin{tabular}{l|c|c}
\hline Component (\%) & 3A & 3B \\
\hline Palm Base Esterquat & 20 & 10 \\
Kemelix 3702X & 20 & 10 \\
Synthesis Compound & 20 & 40 \\
Solvesso 150 & 40 & 40 \\
\hline
\end{tabular}

Figure 9 shows the decrease in differential pressure from 15 to 5 psi after injection of $10 \mathrm{ppm}$ of NI-demulsifier for $2 \mathrm{hrs}$ duration. This indicates sustainability performance overtime where lesser injection rate would be implemented in demulsifier injection system at oilfield offshore surface facilities which also implies that higher temperatures of $60{ }^{\circ} \mathrm{C}$ is favored for better separation with water-in-oil content reduced from $13 \%$ to $2-3 \%$. Further increased in NI-demulsifier to $25 \mathrm{ppm}$ reduce the water-in-oil content further to $0.9 \%$. The NI-Demulsifier used is non-acidic base chemical as it does not change the $\mathrm{pH}$ conditions overtime during the $2 \mathrm{hrs}$ period thus will have less impact towards corrosion problems.

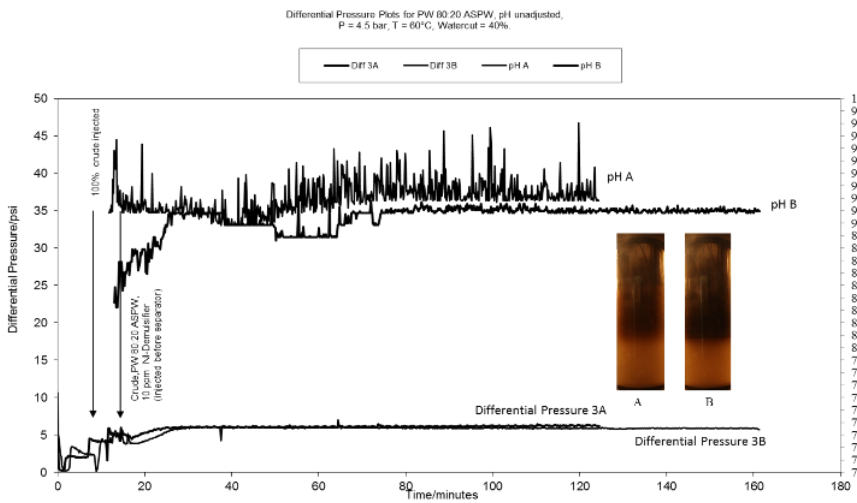

Fig. 9: Crude oil A differential pressure of produced ASP ratio PW: ASPW (80:20), Pressure $=4.5 \mathrm{bar}$, Temperature $=60^{\circ} \mathrm{C}$, water cut $=40 \%$ after treatment with NI-Demulsifier

\section{Conclusion}

The NAs crude oil is expected to produce sodium carboxylatestabilised emulsions in the laboratory when mixed with its PW under current field conditions. Addition of ASP injection water exacerbated high $\mathrm{pH}$ condition in which induced the formation of microemulsion. For ASP-EOR scenario, crude oil A is found to give much more issues in W/O microemulsion as compared to crude oil B. The NI-Demulsifier is able to dehydrate crude oil under the ASP tests. Lower concentrations of NI-Demulsifier and increasing temperature to $60{ }^{\circ} \mathrm{C}$ resulted in greatly improved oilwater separation in the tests ASP flood water. Standing times for oil-water separation with a sharp interface indicates the possibility of using a static tank in the field to aid additional residence time required for adequate oil-water separation.

\section{Acknowledgement}

Authors would like to thank PETRONAS Research Sdn Bhd personnel who directly or indirectly involved in this research. Technical guidance provided by EOR Value Assurer and lastly the authors also wish to thank PETRONAS Management for their permission to publish this paper.

\section{References}

[1] Abdel-Raouf, M. E. S. (2012). Factors Affecting the Stability of Crude Oil Emulsions. In M. E.-S. Abdel-Raouf, Crude Oil Emulsions - Composition Stability and Characterization, InTech, 183204.

[2] Shehzad, F., Hussein, I. A., Kamal, M. S., Ahmad, W., Sultan, A. S., Nasser, M. S. (2017). Polymeric surfactants and emerging alternatives used in the demulsification of produced water: A Review. Polymer Reviews, 58, 63-101.

[3] Rajak, V. K., Singh, I., Kumar, A., Mandal, A. (2016). Optimization of separation of oil from oil-in-water emulsion by demulsification using different demulsifiers. Petroleum Science and Technology, 34, 1026-1032.

[4] Hirasaki, G. J., Miller, C. A., Raney, O. G., Poindexter, M. K., Nguyen, D. T., Hera, J. (2010). Separation of produced emulsions from surfactant enhanced oil recovery processes. Energy \& Fuels, 25, 555-561

[5] Oseghale, C. I., Akpabio, E. J., Udottong, G. (2012). Breaking of oil -water emulsion for the improvement of oil recovery operations in the niger delta oilfields. International Journal of Engineering and Technology, 2, 1854-1860.0

[6] Grbović, L., Pavlović, K., Vasilijevic, B., Kuhajda, K., Popsavin, M., Milic, J., Ćirin-Novta, V. (2012). Fractionation of complex mixtures of naphthenic acids, their characterization and biological. Journal of the Serbian Chemical Society, 77, 147-157.

[7] Dyer, S. J., Graham, G. M., Arnott, C. (2003). Naphthenate scale formation-examination of molecular controls in idealized system," SPE Oilfield Scale Symposium, Aberdeen, UK, 1-13.

[8] Molinier, V., Loriau, M., Lescoulié, S., Martin, B., Gingras, J. P., Passade-Boupat, N. (2016). Quantification of the tetraprotic acids content in oil prediction of naphthenate deposit risk. IPTC-18704MS.

[9] Kang, W. L.; Liu, Y.; Qi, B. Y.; Liao, G. Z.; Yang, Z. Y.; Hong, J. C. (2000). Interactions between alkali surfactant polymer and their effects on emulsion stability. Colloid. Surf. A 175, 243-247.

[10] Wu, J., Xu, Y., Dabros, T., Hamza, H. (2003). Effect of demulsifier properties on destabilization of water-in-oil emulsion. Energy \& Fuel, 17, 1554- 1559 .

[11] Zhang, Z., Xu, G. Y., Wang, F., Dong, S. L., Li, Y. M. (2004). Characterization and demulsification of poly (ethylene oxide)block-poly (propylene oxide)-blockpoly(ethylene oxide) copolymers J. Colloid Interface Sci, 277, 464-470.

[12] Atta, A. A., Al-Shafy, H. I., Mohamed, Z. M. (2011). Application of hydrophobically modified water-soluble polyacrylamide conjugated with poly(oxyethylene)-copoly (oxpropyleene) surfactant as emulsifier, Polym. Adv. Technol., 22, 1879-1887.

[13] Borhan, N., Salleh, I., Ibrahim, J. M. B. M., Farrell, A. R., Nichols, D. A., Graham, G. M. (2016). Investigation of Naphthenates Crude Oil Types and Behaviour to Induce Soaps-Microemulsion and Soap-Fines Foam in Malaysian EOR Fields. In International Petroleum Technology Conference. IPTC-18948-MS

[14] Mohammed M.A., Sorbie K.S. (2010). Thermodynamic modelling of calcium naphthenate formation: Model prediction and experimental results. Colloids \& Surfaces A: Physicochem. Eng. Aspects, $369,1-10$. 